УДК 316.33

\title{
РОЛЬ И МЕСТО ПАБЛИК РИЛЕЙШНЗ В СТРУКТУРЕ ИНФОРМАЦИОННО-КОММУНИКАЦИОННОГО ПРОСТРАНСТВА СОВРЕМЕННОЙ РОССИИ
}

\author{
(C) 2013 г. A. Ф. Невоструева
}

\section{Пермский государственный политехнический университет}

Статья посвящена выяснению основного смысла деятельности особого сочиального института в информационно-коммуникачионном пространстве современного российского общества - «паблик рилейшнз». Анализируется процесс становления его как самостоятельной научной дисциилины сочиологической отрасли знания, места и роли в практическом осуществлении социальной коммуникащии.

Ключевые слова: PR; паблик рилейшнз; соџиальное знание; социальный институт; модели паблик рилейшнз; институцииализащия.

Article is devoted to clarifying the substantive content of particular social institution in informational and communication space of nowadays Russian society - the public relations in the making as an independent scientific discipline of sociological knowledge field, its place and role in the practical implementation of social communication.

Key words: PR; public relations; social knowledge; social institution; a model of public relations; institutionalization.

Проблематика научности паблик рилейшнз (в дальнейшем мы будем использовать аббревиатуру PR) в современных условиях трансформации российского общества, их роль и место в коммуникативных процессах представляет особый интерес. Реальная PRпрактика, как часть нематериальной экономики, связана с идеологической, управленческой и коммуникационной проблематикой. В условиях глобализации информационнокоммуникационного пространства владение информацией приобретает политическое и экономическое значение. Как известно, кто контролирует потоки информации, тот и пытается реально управлять массовым сознанием. Информация - это и идеологический pecypc, и ресурс важнейших конкурентных преимуществ.

Анализ генезиса социального института PR свидетельствует об осуществлении им в качестве особого типа социальной коммуникации взаимосвязи между другими социальными институтами, научном управлении общественным мнением и контроле над эффективностью информационно-коммуникационной политики [13, с. 82-106].

PR как социальный и научный феномен базируется на системе социологических знаний, понятийных категорий, и поступательно трансформируется в отдельную научную дисциплину. Сам термин «паблик рилейшнз» (англ. public relations, фp. relations publiques) переводится как «общественные отношения», на русском языке произносится как «отношения с общественностью», а в Государственном стандарте высшего образования третьего поколения обучение по специальности обозначено как «реклама и связи с общественностью».

В нашей стране термин «паблик рилейшнз» вошел в общественный дискурс в начале 90-х гг. XX в., и стремительно завоевал высокий индекс упоминания в коммуникационном пространстве (уже в 1999 г. он попадает в список «самых популярных слов года»). Благодаря PR, была создана основа 
для появления организационных структур, обеспечивающих деятельность организаций в условиях новой политической, экономической и культурной ситуации. Коммуникация выходила на первый план в проблемах взаимодействия всех социальных институтов современного общества, что можно аргументировать сравнительной таблицей в поисковой системе «Google».

Как видно из данной таблицы, количество web-страниц за 10 лет в сети Интернет по терминам, связанным с коммуникативной тематикой, увеличилось от 63 до 318 раз. В системе «Yandex» эти показатели еще более высокие.

Современные исследователи, при всей палитре взглядов на PR, сходятся в принципиальном мнении, что PR, как наука, при всех «детских болезнях», активно развивается. Убедительным аргументом для нашей гипотезы становления PR как науки служит мнение Д. Грюнига, одного из руководителей Международного института PR: «Паблик рилейшнз является юной областью научных исследований, хотя, как социальная практика, она существует, по крайней мере, 100 лет, а, возможно, и тысячи лет, что зависит от того, как мы определяем происхождение этой деятельности» [20, с. 28].

Трудность теоретических обобщений и научной концепции, на наш взгляд, заключается в том, что PR, как отрасль научного знания, выросла из социальной практики, и научное сообщество по-прежнему относится к ней только как к дисциплине прикладного характера, обучающей использовать модели, приёмы, инструменты и технологии. К сожа- лению, несмотря на все фундаментальные предпосылки и развитие PR, для многих ученых, практиков идентичными остаются что PR, что маркетинг, что реклама. Это не вполне взвешенное убеждение свидетельствует о подмене сущности PR, базирующейся на социальных смыслах и информации.

Формирующаяся научная дисциплина пиарология «спотыкается» о некоторое модное сетование тех, кто полагает, что PR - это особый новый вид манипуляции общественным сознанием и набор инструментов, не более. Подобной точке зрения можно найти объяснение. Она связана с различными историческими, идеологическими, этическими и профессиональными причинами, проблемой нравственного самоопределения PR-специалиста, сформированностью компетентностей и мировоззрения.

Как показывает анализ, негативные общественные стереотипы восприятия PR связаны с популистскими методами работы с общественностью, с чертами манипулятивного управления политическими процессами, с манипулятивными технологиями выборов всех уровней законодательной и исполнительной власти начала 90-х гг. ХХ в. и сохраняющимися в современный период. Отсутствие внятной концепции развития страны, расслоение общества, бедность, коррупция в государственных структурах власти, недоверие судебной системе, зачаточное состояние гражданского общества, несвобода средств массовой информации, попавших из объятий всеобъемлющего контроля государства в еще более мощный прессинг частного капитала, игнорирование общественного мнения, не-

Таблица 1

Динамика изменений популярности коммуникационных терминов в сети Интернет за 10 лет [18, с. 188; 13, с. 19]

\begin{tabular}{|l|c|c|c|}
\hline \multicolumn{1}{|c|}{ Термины } & $\begin{array}{c}\text { июль 2002 г., } \\
\text { кол-во документов }\end{array}$ & $\begin{array}{c}\text { февраль 2008 г., } \\
\text { кол-во документов }\end{array}$ & $\begin{array}{c}\text { ноябрь 2012 г., } \\
\text { кол-во документов }\end{array}$ \\
\hline Коммуникация & 19642 & 1650000 & 6240000 \\
\hline Теория коммуникации & 17464 & 489000 & 4280000 \\
\hline Коммуникология & 12 & 321 & 24700 \\
\hline Коммуникатор & 218571 & 1530000 & 13800000 \\
\hline Коммуникационный & 90556 & 489000 & 6190000 \\
\hline
\end{tabular}


профессионализм и жажда наживы представителей PR-индустрии на «выборной ниве» и др. обстоятельства породили недоверие граждан ко многим социальным институтам. B адрес PR это проявляется в обличениях типа: «это всё только пиар...», «им бы только пропиариться...», «всё делается только для пиара...» и т. п.

Однако мир стремительно меняется, меняется и социальный смысл, статус структуры, формирующей информационную политику государства (организации). При всей неоднородности кадров в области PR компетентные профессионалы социальнокоммуникативной деятельности, образованные - на вес золота. Трудно себе представить PR-образование без участия специалистов-практиков и изучения таких основополагающих дисциплин как: социология, философия, история, политология, культурология, журналистика, этика, психология и др.

Независимо от «принятия» или «неприятия» PR как научной дисциплины, от «обделенности» научным вниманием классической наукой, за последние два десятилетия сформировалась теоретическая обоснованность и методологическая проработанность PR, появились фундаментальные отечественные и зарубежные теоретические работы, в которых аккумулированы новые тенденции PR $[1 ; 2 ; 3 ; 4 ; 5 ; 6 ; 7 ; 8 ; 9 ; 16 ; 19 ; 20]$.

Также, как теория методологии, PR, при всей «приземленности» эмпирического материала, свидетельствует о научно-исследовательском содержании и ростках научных вузовских школ, в частности, Петербургской школы PR, зародившейся на факультете журналистики Санкт-Петербургского университета. Здесь подготовку «пиарменов» на уровне специализации начали в 1991 г., а спустя шесть лет открыли соответствующую специальность $[15$, с. 8]. Один из создателей этой школы, профессор А. Д. Кривоносов отмечает: «...существование самостоятельного профессионального вида деятельности, наличие признанной государством профессии, образовательных структур, дающих образование по специальности требуют и наличия особой науки, которая должна отражать сущностные характеристики такой деятельности, её закономерности, механизмы функционирования» $[11$, с. 49]. В Пермском политехническом уни- верситете (ныне - Пермский национальный исследовательский политехнический университет) специальность «связи с общественностью» на гуманитарном факультете открыта в 1997 г. Как свидетельствует, в том числе и Международный конкурс на получение премии в области развития связей с общественностью PROBA-IPRA GOLDEN WORLD AWARDS 2012 (Санкт-Петербург, декабрь 2012 г.), востребованность и престижность специальности возрастает с каждым годом практически во всех регионах страны.

Автор не склонен идеализировать роль и место PR в системе гуманитарных наук, и, в целом, в структуре информационно-коммуникационного пространства. Вместе с тем, сложность PR как социального института в том, что многие его черты находятся «не на поверхности», они скрыты от прямого восприятия («латентны» — по Р. Мертону), а наука PR связана мощной «кровеносной системой» с социальной реальностью. Глобализация информационно-коммуникационного пространства, многообразие и интенсивность внешних факторов побуждают представителей научного сообщества более предметно исследовать сам феномен PR, историю и перспективы развития. По мере усложнения практики PR идет научный поиск ответов на вызовы времени, связанным с рассмотрением PR в системе нематериальной экономики, функций в менеджменте, интернационализации, взаимовлиянии общественных мнений различных категорий населения, гармонизации взаимодействия государственных институтов власти и общества, так называемого «третьего сектора» - институтами гражданского общества, а также реальным бизнесом.

Методология PR, как уже отмечалось, во многом основана на системе социологических знаний. Именно социология - наука, изучающая общество и общественные отношения - даёт PR теоретическое обоснование для изучения коммуникации на уровне предельно широкого предмета, которым является общество.

Функции и тенденции эволюции, становление базовых дефиниций PR свидетельствуют об их «вписывании» в категориальный аппарат социологии. Во-первых, «коммуникация» является предметом изучения социологической теории. Во-вторых, PR исполь- 
зует ряд научных понятий социологии: «социальный институт», «социализация», «социальная структура», «социальная группа», «социальное действие», «социальная стратификация», «социальный статус», «институциализация», «социальная коммуникация», «массовая коммуникация», «интеракция» (когда социальные явления можно понять лишь на основе анализа тех смыслов, которые люди придают данным явлениям при взаимодействии друг с другом [17, с. 21]), «функционализм», «социальное взаимодействие» и др., имеющих глубокую разработанную теоретическую и инструментальную основу. B-третьих, в PR используются основные методики социологического анализа и изучения целевых групп общественности (методики включенного наблюдения, количественных и качественных опросов общественного мнения, межличностных отношений, измерения и оценки целей PR и др.). Выражаясь образно - социология вырастила научную «дочку». Тем самым «...можно предположить, что в дальнейшем взаимодействие между различными направлениями социологии и паблик рилейшнз будет происходить не только в плане использования методик социологических исследований в $\mathrm{PR}$, но и в плане применения различных форматов конструкции материалов и стилистики дискурса» [21, с. 241].

Таким образом фундаментальный вектор развития теории и методологии науки PR позволяет перейти от утопических предвзятых представлений о ней к осмыслению трудностей и проблем, места и роли в гуманитарном цикле дисциплин и социальной практике. На этом фоне более явными становятся основные процессы усиления идеологической роли и места PR в системе информационнокоммуникационного пространства, несмотря на тот неоспоримый факт, что обладание информацией еще совсем недавно являлось преимуществом СМИ.

В ходе реформирования всех сторон жизни страны, с целью влияния на мнение и поведение граждан, по мере вхождения новой России в мировое сообщество и использование накопленного им опыта, создаются и эволюционируют различные PR-структуры: пресс-службы, пресс-секретари, пресс-центры, колл-центры, отделы и департаменты по связям с общественностью, консалтинговые агентства и др., как неотъемлемая часть информационного процесса. Учитывая опыт социальных коммуникативных практик, некоторые из государственных и коммерческих структур формируют PR в качестве самостоятельного направления стратегической управленческой деятельности, принимая во внимание природу коммуникаций между людьми в различных ситуациях.

В условиях чрезвычайно плотного и разнообразного информационного потока (по современным подсчетам, к XIX в. объем информации удваивался каждые 50 лет, с 1950 г. - каждые 10 лет, с 1970 г. - каждые 5 лет, с 1990 г. - ежегодно) [7, с. 116] в сфере PR на первый план выдвигается именно проблема осмысленной коммуникации, позволяющей современным организациям доверительно взаимодействовать с целевыми группами общественности для достижения наибольшей эффективности понимания. Известный французский теоретик в области PR и успешный практик, профессор Сорбонны Ж. Бодуан вводит понятие «комплицитность» в отношении содержания такой коммуникации, что «...означает демонстрировать свою деятельность вокруг общественности и работать так, чтобы эту деятельность не только узнавали, но и принимали» [4, с. 117].

Известно несколько моделей коммуникативного взаимодействия, авторы которых, в зависимости от своей области деятельности, выдвигают на первый план ту или иную сферу коммуникации: кибернетическая (информационно-кодовая) модель Н. Винера, модифицированная К. Шенноном, У. Уивером, М. Дефлёром; лингвистическая (семантическая) модель Р. О. Якобсона, Л. Баркера, Л. Выготского, Ю. Лотмана, И. Эвен-Зохара; техногенная модель М. Маклюэна, Д. Маккуэйла; «мифологическая» модель К. ЛевиСтросса, М. Элиаде, Р. Барта.

На наш взгляд, в современных моделях коммуникации в сфере PR более продуктивной является «социетальная» модель, учитывающая в первую очередь её социальную природу, когда получателем сообщений выступает сообщество, социум. К ним можно отнести классическую «однолинейную» модель Г. Лассуэлла, дополненную П. Ла- 
зерсфельдом; «многоступенчатую» модель Э. Каца и У. Шрамма, получившую развитие в работах Д. Клаппера.

В информационном процессе Российской Федерации, в основном, используется модель «двухсторонней асимметричной коммуникации», при которой на первый план выходит установление двухсторонней связи с общественностью, а большую выгоду получает от этих связей только сама организация или её лидер. И в меньшей степени отдается предпочтение модели «двухсторонней симметричности», основанной на необходимости взаимопонимания, «социальной ответственности», партнерства на всех уровнях, обоюдной пользе, что характерно для содержания развития информационного общества современного типа. Например, во Франции в последнее время получила распространение оригинальная модель коммуникации, получившая название «модель близости», основанная на идеях репутационного менеджмента: коммуникационные послания (логотип, слоган, ценности) и коммуникационную режиссуру (спонсорство, меценатство), которая может быть использована в современном информационно-коммуникационном пространстве России из-за сходства основных черт менталитета российского и французского народов [12, с. 62-63].

Определяя сущность, цели и задачи PR, т. е. онтологические основания существования этого социального института можно выделить четыре основных подхода: функциональный (где на первый план выходит функция управления), деятельностный (практическая деятельность, направленная на достижение определенных целей и решение практических задач), интегративный (определенный компромисс между первыми двумя) и прогностический. Основным недостатком данных подходов является выдвижение на первый план и в качестве решающего компонента какой-то одной из сторон осуществления отношений с общественностью. На наш взгляд определение их сущности можно дать на основе понимания социальной коммуникации, её всеобъемлющего характера, и тем самым PR можно охарактеризовать, как идеологическую институциализированную форму социальной коммуникации, органич- но включенную в информационно-коммуникационное пространство страны.

Целью PR является формирование эффективной системы публичной коммуникации социальных объектов, а также обеспечение благоприятных условий для установления партнерских, доверительных (комплицитных) отношений, как между социальными институтами, так и включение в эти отношения общественности, т. е. в конечном счете - стабильное существование общества в целом, способность его совершать продуманные действия в условиях трансформации российского общества, его динамизма и альтернативности.

Cфера PR полисубъектна и неоднозначна. Это определяется особенностями исторического периода, смыслами развития страны, уровнем индустрии коммуникационных средств и самим информационно-коммуникационным пространством. В условиях рыночных отношений в PR включается: идеологическая, управленческая составляющая, формирование общественного мнения, имиджа и репутации, создание миссии организации и корпоративной политики, информирование общественности, целевых групп, позиционирование социально ответственного бизнеса, взаимодействие со средствами массовой информации, антикризисные действия и др.

Важно обратить внимание на тот факт, что в начале 1990-х гг. возобладала концепция, согласно которой PR отождествлялся с филологической наукой и обучение специальности было отнесено, организовывалось, в основном, на базе филологических кафедр вузов. Согласно этой концепции, PR представлялся как прикладная интегрированная междисциплинарная область знаний. Но мир стремительно меняется, при этом смыслово меняется социальная роль и место PR. Проблематика коммуникации давно переросла рамки традиционных исследований естественных и гуманитарных наук, и представляет собой интерес, практически, для всей системы научного познания.

Таким образом, в современной российской действительности PR как социальный феномен, как самостоятельный социальный институт изучает общество, играет ключевую роль интегративного инструмента в из- 
учении конкретных процессов и явлений социальной жизни. Он аккумулирует новые идеологические тенденции в информационно-коммуникационном пространстве страны, взаимовлияние общественных мнений между различными категориями населения, гармонизирует взаимодействие всех акторов коммуникационного процесса. Время диктует необходимость подняться на новый уровень осмысления и понимания сфер компетенций филологической и социологической науки и, как следствие, представляется необходимость создания автономной научной дисциплины — паблик рилейшнз (PR).

\section{Литература}

1. Алёшина И. В. Паблик рилейшнз для менеджеров. - М.: ЭСМОС, 2002. - 480 с.

2. Бернейз Э. Паблик рилейшнз. - М.: Наука, 1994. - 286 с.

3. Блэк С. Паблик рилейшнз. Что это такое? - М.: СП АСЭС, 1990. — 240 с.

4. Бодуан Ж.-П. Управление имиджем компании. Паблик рилейшнз: предмет и мастерство. - М.: ИНФРА-М, 2001. - 233 с.

5. Василенко А. Б. ПИАР крупных российских корпораций. - М.: ГУ ВШЭ, 2002. $-304 \mathrm{c}$.

6. Гавра Д. П. Основы теории коммуникации. - СПб.: Роза мира, 2005. - 347 с.

7. Еляков А. Д. Информационная перегрузка людей. // Социологические исследования. - 2005. - №5. - С. 114-121.

8. Катлип С. М., Сентер А. Х., Брум Г. М. Паблик рилейшнз. Теория и практика. Уч. пособие. - 8-е изд. - М.: Изд. дом «Вильямс», 2001. - $624 \mathrm{c.}$

9. Китчен Ф. Дж. Паблик рилейшнз. Принципы и практика. - М.: Юнити, 2004. $-454 \mathrm{c}$.

10. Коханов Е. Ф. Теоретические и методологические основы PR-деятельности (со- циологический аспект). — М.: РИП-Холдинг, 2004. - 208 c.

11. Кривоносов А. Д. Структурная модель российской пиарологии. // Подготовка PRспециалиста в вузе: тенденции и перспективы. Материалы 4-й Всерос. науч.-практич. конференции. - Екатеринбург, 2009. - С. $49-55$.

12. Лебедева Т. Ю. Паблик рилейшнз: системные модели, технологии. - М.: Изд-во МГУ, 2007. - $224 \mathrm{c}$.

13. Невоструева $A$. Ф. Паблик рилейшнз в системе социологического знания. Пермь: Изд-во ПНИПУ, 2010. - 258 с.

14. Ньюсом Д., Тёрк Дю., Крукеберг Д. Bсё о PR: Теория и практика паблик рилейшнз. - М.: ИД «Инфра-М», 2001. $628 \mathrm{c}$.

15. Петербургская школа PR: от теории к практике. // Сб. статей. Вып. 5. - СПб.: Издво Санкт-Петербург. ун-та, 2007. - 122 с.

16. Почепцуов Г. Г. Паблик рилейшнз для профессионалов. - М.: Рефл-бук, 2000. $624 \mathrm{c}$.

17. Смелзер Н. Социология. - М.: Феникс, 1994. - $688 \mathrm{c}$.

18. Тулузкова В. И., Богуславская В. В. Термины как средство конструирования предметной области «Теория и практика коммуникации» в российской науке. // Теория коммуникации и прикладная коммуникация. Вестник РКА. Вып. 1. - Ростов н/Д, 2002. C. 185-192.

19. Чумиков А. Н., Бочаров М. П. Связи с общественностью: теория и практика. - М.: Дело, 2003. - 496 с.

20. Шишкина М. А. Паблик рилейшнз в системе социального управления. - СПб.: «Паллада-медиа», 2002. - 444 с.

21. Энциклопедия паблик рилейшнз. М.: Консалтинговая группа «ИМИДЖ-Контакт»; Париж: IEERP-L'Harmattan, 2009. 297 c. 


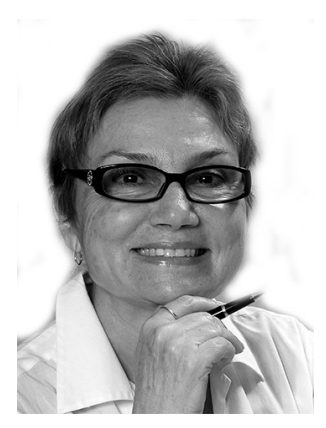

Антонина Федоровна Невоструева - кандидат социологических наук, доцент кафедры иностранных языков и связей с общественностью Пермского национального исследовательского политехнического университета.

Antonina Fedorovna Nevostrueva - Ph.D., Candidate of Sociology, docent at the Permian National Research Polytechnic University's department of foreign languages and public relations.

614990, Пермь, Комсомольский пр., 29

29 Komsomolskiy ln., 614990, Perm, Russia

Тел./факс: 7 (342) 21-98-30; e-mail: nik772@yandex.ru

\section{Поисковые гранты 2014 года \\ по Программе научно-технической модернизации \\ и повышению квалификации молодых ученых}

Региональный общественный Фонд содействия отечественной науке объявляет конкурс на присуждение поисковых грантов по Программе научно-технической модернизации и повышению квалификации молодых ученых России.

В рамках данного конкурса в 2014 г. будут выделяться гранты на проведение научных исследований по созданию новых материалов и приборов, а также на разработку новых технологий для космических приложений.

Размер каждого гранта - 500000 рублей.

Для участия в конкурсе приглашаются научные коллективы, возглавляемые известными российскими учеными. В коллективе должно быть не менее трех молодых ученых — аспирантов, кандидатов наук (до 40 лет) и докторов наук (до 50 лет), имеющих существенный научный задел по заявленной тематике проекта (статьи, доклады на крупных международных конференциях, патенты на изобретения, свидетельства о регистрации компьютерных программ и т. д.).

По всем интересующим вопросам можно обращаться к секретарю Фонда - Марии Михайловне Маркиной, тел.: +7 (495) 9607178.

Информация о Программе на сайте Фонда: http://www.science-support.ru/news/news2013-nota.html 